\title{
EFFECT OF CURRENT NEONATAL TRANSPORT SERVICES ON SHORT TERM OUTCOME OF OUTBORN NEONATES
}

Ekta Jasuja Sundrani1 ${ }^{1}$ Umesh Katariya², Swati Mulye³, Dinesh Yadav ${ }^{4}$, Dr. Durga Shankar Patel5, Omprakash Sundrani ${ }^{6}$

${ }^{1}$ Consultant Paediatrician, Department of Paediatrics, Avanti Multispecialty Hospital, Raipur, Chhattisgarh, India.

${ }^{2}$ Consultant Paediatrician, Indore, Madhya Pradesh, India.

3 Professor, Department of Paediatrics, SAIMS, Indore, Madhya Pradesh, India.

${ }^{4}$ Consultant Paediatrician, Department of Paediatrics, Siddhi Vinayak Hospital, New Delhi, India.

${ }_{5}^{5}$ Associate Professor, Department of Anaesthesiology, GMC, Ambikapur, Chhattisgarh, India.

${ }^{6}$ Associate Professor, Department of Anaesthesiology and Critical Care, Pt. JNMMC, Raipur, Chhattisgarh, India.

\begin{abstract}
BACKGROUND
ABSTRACT

Neonatal transport is the most important component of regionalized perinatal health care system, but still there are no legal regulations on regionalized perinatal care and transport of sick new-borns in our country. Although hospital-based deliveries have increased, level I \& II centers still have extremely limited resources. The need for the systematic transport from these far situated, level I \& II centers with inadequate staffing and equipment, indicates the need for better regionalization with special care newborn units at district level. The present study was done to assess the effect of available Neonatal Transport System on morbidity and mortality of out born neonates; including modes, organized transport, special needs and care during transport.
\end{abstract}

\section{MATERIALS AND METHODS}

In this prospective observational study, we included all neonates (from birth to 28 days of life) born outside SAIMS hospital and referred to SAIMS, Neonatal Intensive Care Unit (NICU) for tertiary care centre for a period of one year. Cases who were found to be dead at the time of arrival to the institute were excluded from the study.

\section{RESULTS}

We observed that immediate and long-term outcome varies with the place of delivery, mode of transport, travelling distance and initial stabilization of the baby. We also found that biochemical and temperature disturbances are more common in babies transported on their own and a specialized neonatal transport service could improve the survival of these new-borns.

\section{CONCLUSION}

All Neonatal health care facilities should have some basic referral guidelines so that events like hypothermia, hypoglycaemia and hypoxia can be prevented.

\section{KEY WORDS}

Neonatal Transport, Hypothermia, Hypoglycaemia.

HOW TO CITE THIS ARTICLE: Sundrani EJ, Katariya U, Mulye S, et al. Effect of current neonatal transport services on short term outcome of outborn neonates. J. Evolution Med. Dent. Sci. 2019;8(01):81-87, DOI: 10.14260/jemds/2019/18

\section{BACKGROUND}

Neonatal transport is an evolving concept worldwide. In utero transport is the safest transport but unfortunately preterm deliveries, perinatal illnesses and congenital malformations cannot be anticipated always, resulting in a continuing need for transferring the baby after delivery ${ }^{1}$. High risk neonates, which are delivered at Level I care centre and transferred, have a significantly greater risk of death due to severe respiratory distress syndrome (RDS), intra ventricular haemorrhage (IVH) and nosocomial infections than new-borns born in a Level III Care centre itself. ${ }^{2-3}$ These babies are often critically ill, and outcome is partly dependent on the effectiveness of Transport system. ${ }^{4}$

'Financial or Other Competing Interest': None.

Submission 25-06-2018, Peer Review 24-10-2018,

Acceptance 30-10-2018, Published 07-01-2019.

Corresponding Author:

Dr. Durga Shankar Patel,

H. No. 19, Phase I, Harsh Nihar,

DaldalSconi, Mowa,

Raipur-492001, Chhattisgarh, India.

E-mail:sundraniop@rediffmail.com

DOI: $10.14260 /$ jemds $/ 2019 / 18$

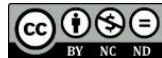

Adequate neonatal transport is a key component of care of the sick new-born infant who requires referral to tertiary care centers. When a new-born infant is referred, transport may interfere with several aspects of his/her homeostasis, such as thermo- regulation, metabolic stability, fluid and electrolyte balance and cardio respiratory status among others 5 .

A Successful Transport Actually Involves Two Transitions of Care of Neonates

- From the referring hospital staff to the transport team,

- From the transport team staff to the accepting hospital staff.

Transportation of the sick or preterm babies to a centre with expertise and facilities for the provision of multi organ intensive care has been shown to improve outcomes. ${ }^{6}$ In present study, an attempt has been made to address few questions related with neonatal transport: differences between self-transport and organized transport, different types and modes of transport, organization of a neonatal transport system, different special care needs to be given for a sick neonate during transport. The present work was done to assess the associations between mortality and condition of new-borns delivered outside, at arrival to a tertiary care centre. 


\section{Aims and Objectives}

1. To study the effect of Neonatal Transport System on morbidity and mortality of out born neonates.

2. To analyse the effect of different variables of neonatal transport on immediate outcome of new-born (in terms of): mode, place, distance and duration of transport.

3. To assess the risk of hypothermia and hypoglycaemia in out born neonates.

4. To assess the status of neonatal transport in out born neonates brought to NICU.

\section{MATERIALS AND METHODS}

This prospective observational study was carried out at Department of Paediatrics of Shri Aurobindo Institute of Medical Sciences (SAIMS) after approval from institutional ethical committee. All neonates (from birth to 28 days of life) born outside SAIMS hospital and referred to SAIMS, Neonatal Intensive Care Unit (NICU) for tertiary care centre for a period of one year were included in this study. Cases found to be dead at the time of arrival to the institute were not included in our study.

A Detailed History Including neonate variables like gestational age, sex, birth weight, place and mode of delivery along with birth attendant were noted down. Gestational age of the baby being transported was confirmed by Modified Ballard's score. Data regarding transport was taken from the case-sheets. The distance and the time taken for the baby to reach the hospital from the referring unit was taken for this study. To evaluate the conditions of mode of transport, the equipment and medications used for new-born care, care provided before and during transport including IVF and feeding during transport, accompanying person with additional skills and referral notes along with communication pattern with the two hospitals were analysed. Also, estimation of different clinical parameters of the neonate at the time of arrival.

Temperature of the upper abdominal skin was measured by the skin probe attached in the radiant warmer which was calibrated with the clinical thermometer. After taking the temperature babies were classified according to WHO classification of hypothermia in normothermic, mild, moderate \& severe hypothermia. Babies who were found to be normothermic were assessed for the other complaints \& were treated accordingly.

Then Neonate's blood sugar estimation was performed by using a Glucometer. Blood for sugar estimation was obtained from the lateral aspect of the neonate's heel after prewarming by rubbing with the palm for 30 seconds. If the Glucometer reading was $<40 \mathrm{mg} / \mathrm{dl}$ then $1 \mathrm{ml}$ of venous blood was drawn immediately from any of the superficial vein of the hand using a 24-gauge disposable needle. The blood was put into a nonheparinised small vial; labelled and sent to the Lab. Sooner the result was recorded in the predesigned Performa. Meanwhile the neonate was given 2 $\mathrm{ml}$ per kg of $10 \%$ dextrose intravenously as a bolus and $10 \%$ dextrose as maintenance fluid was continued, that provided glucose at the rate of $6-8 \mathrm{mg} / \mathrm{kg} /$ minute.

The patients were followed till their discharge from the institution. The outcome was recorded as expired, discharged or left against medical advice. The duration of stay was mentioned in days. Expired patients were assigned cause of death after discussion with the unit head. At the end of stay the infant was assigned a final diagnosis as per neonatal definition approved by the national neonatology forum of India.

All the observations were recorded and tabulated and the data were entered into the computer database and responses were calculated and analysed by using statistical software SPSS version 11.0. Prevalence of an outcome variable along with 95\% confidence limits was calculated. Both, descriptive and inferential statistics were used to measure the effect of hypothermia and hypoglycaemia in the neonates on arrival at the center to identify the effectiveness of transportation system and clinical profile of out born neonates referred for hospitalization. The descriptive statistics were determined for age, weight, temperature, random blood sugar. The Nonparametric test, Pearson's Chi-Square test was used to observe the association of hypothermia and hypoglycaemia with selected demographic variables. The probability value from $p<0.05$ to $p<0.02$ was considered as significant while $\mathrm{p}<0.01$ and from $\mathrm{p}<0.001$ to $\mathrm{p}<0.009$ were considered as highly significant.

\section{RESULTS}

In this study, out of total 324 babies $37.3 \%$ (121) were referred from rural area, while urban babies constituted $62.7 \%$ (203) and among them $64.2 \%$ were male and $35.8 \%$ were female. As per gestational age 163(50.3\%) were preterm and 161 (49.7\%) were term babies

Approximately two-third $(234,72.2 \%)$ of the total babies were reported hypothermic $\left(\leq 36.4^{\circ} \mathrm{C}\right)$, while $21.3 \%$ (69) babies found hypoglycaemic $(\leq 40 \mathrm{mg} / \mathrm{dl})$ Incidence of hypoxia $\left(\mathrm{SpO}_{2}<75 \%\right)$ was $21.9 \%$ (71 babies), while poor perfusion ( $\geq 3 \mathrm{sec}$ ) was noted in $19.1 \%$ (62) babies.

Out of these 234 babies who were detected with hypothermia at the time of admission, $17.1 \%$ (40 babies) had mild hypothermia $\left(36-36.4{ }^{\circ} \mathrm{C}\right), 76.5 \%$ (179 babies) had moderate hypothermia $\left(32-36^{\circ} \mathrm{C}\right)$ and $6.4 \%$ (15 babies) had severe hypothermia $\left(<32^{\circ} \mathrm{C}\right)$.

\section{\begin{tabular}{l|l|l|l|} 
Disease & Mean & Standard Deviation & Standard Error
\end{tabular}}

\begin{tabular}{|c|c|c|c|}
\hline Hypothermia & 35.33 & 1.54 & 0.09 \\
\hline Hypoglycaemia & 98.2 & 86.05 & 4.78 \\
\hline \multicolumn{3}{|c|}{ Table 1 } \\
\hline
\end{tabular}

Table 1 Highlights the descriptive statistics like mean, standard deviation and standard error of selected conditions i. e. hypothermia and hypoglycaemia.

In our study maximum number of deliveries (96\%), were conducted by trained personnel either a doctor or a trained nurse, while $2.8 \%$ were attended by a dai and $1.2 \%$ by some untrained personnel or relatives.

Most of the subjects $(85,57.8 \%)$ of less than or equal to 1 day of age had moderate hypothermia and $8.2 \%$ had severe hypothermia. In babies with age greater than 1 day (54.60\%), more than half $(94,53.1 \%)$ had suffered from moderate hypothermia. Severe hypothermia was reported in few $(1.7 \%)$ babies with age more than one day. 


\begin{tabular}{|c|c|c|c|c|}
\hline \multirow{2}{*}{ Place of Delivery } & \multicolumn{3}{|c|}{ Hypothermia } & \multirow{2}{*}{$\begin{array}{c}\text { Normothermic } \\
36.4^{\circ} \mathrm{C}\end{array}$} \\
\hline & $<32$ - $\mathrm{C}$ & $32-36 \div \mathrm{C}$ & $36-36.4^{\circ} \mathrm{C}$ & \\
\hline Home $(4.9 \%)$ & $1(6.3 \%)$ & $8(50.0 \%)$ & $1(6.3 \%)$ & $6(37.5 \%)$ \\
\hline District Hospital (48.1\%) & $8(5.1 \%)$ & $94(60.3 \%)$ & $20(12.8 \%)$ & $34(21.8 \%)$ \\
\hline Primary Health Center $(9.0 \%)$ & $1(3.4 \%)$ & $20(69.0 \%)$ & $1(3.4 \%)$ & $7(24.1 \%)$ \\
\hline Private Nursing Home (37.0\%) & $5(4.2 \%)$ & $56(46.7 \%)$ & $18(15.0 \%)$ & $41(34.2 \%)$ \\
\hline Tertiary Center $(0.9 \%)$ & $0(0.0 \%)$ & $1(33.3 \%)$ & $0(0.0 \%)$ & $2(66.7 \%)$ \\
\hline Total & $15(4.6 \%)$ & $179(55.2 \%)$ & $40(12.3 \%)$ & $90(27.8 \%)$ \\
\hline \multicolumn{5}{|c|}{$\chi_{12}^{2}=13.61_{[p>0.05 ; \text { Two-Tailed] Significant }}^{*}$} \\
\hline \multicolumn{5}{|c|}{ Table 2. Distribution according to Place of Delivery of New-Borns } \\
\hline
\end{tabular}

\begin{tabular}{|c|c|c|c|c|}
\hline \multirow{2}{*}{ Mode of Transport } & \multicolumn{3}{|c|}{ Hypothermia } & \multirow{2}{*}{$\begin{array}{c}\text { Normothermic } \\
>36.4^{\circ} \mathrm{C} \\
\end{array}$} \\
\hline & $<32 \mathrm{O} C$ & $32-36 \div \mathrm{C}$ & $36-36.4^{\circ} \mathrm{C}$ & \\
\hline Ambulance (50.9\%) & $7(4.2 \%)$ & $95(57.6 \%)$ & $18(10.9 \%)$ & $45(27.3 \%)$ \\
\hline Four Wheelers (32.1\%) & $4(3.8 \%)$ & $61(58.7 \%)$ & $12(11.5 \%)$ & $27(26.0 \%)$ \\
\hline $\operatorname{Van}(6.2 \%)$ & $4(20.0 \%)$ & $11(55.0 \%)$ & $1(5.0 \%)$ & $4(20.0 \%)$ \\
\hline Auto $(6.2 \%)$ & $0(0.0 \%)$ & $9(45.0 \%)$ & $4(20.0 \%)$ & $7(35.0 \%)$ \\
\hline Two Wheelers (4.6\%) & $0(0.0 \%)$ & $3(20.0 \%)$ & $5(33.3 \%)$ & $7(46.7 \%)$ \\
\hline Total & $15(4.6 \%)$ & $179(55.2 \%)$ & $40(12.3 \%)$ & $90(27.8 \%)$ \\
\hline \multicolumn{5}{|c|}{$\chi_{12}^{2}=26.53_{[\mathrm{p}<0.009 ; \text { Two-Tailed }] \text { Highly Significant }}{ }^{*}$} \\
\hline \multicolumn{5}{|c|}{ Table 3. Distribution according to Mode of Transport of New-Borns } \\
\hline
\end{tabular}

\begin{tabular}{|c|c|c|c|c|c|c|}
\hline \multirow{2}{*}{$\begin{array}{l}\text { Travelling } \\
\text { Distance } \\
\text { (in Km) }\end{array}$} & \multicolumn{3}{|c|}{ Hypothermia (in ${ }^{\circ} \mathrm{C}$ ) } & \multirow{2}{*}{$\begin{array}{c}\text { Normothermic } \\
36.4\end{array}$} & \multirow{2}{*}{$\begin{array}{c}\text { Hypoglycaemia } \\
\leq 40 \\
\mathrm{mg} \backslash \mathrm{dl}\end{array}$} & \multirow{2}{*}{$\begin{array}{c}\text { Normoglycemia } \\
>40 \\
\text { mg } \backslash \mathrm{dl}\end{array}$} \\
\hline & $<32$ & $32-36$ & $36-36.4$ & & & \\
\hline$\leq 20(45.40 \%)$ & $2(2.7 \%)$ & $14(18.7 \%)$ & $17(22.7 \%)$ & $42(56.0 \%)$ & $11(14.7 \%)$ & $64(85.3 \%)$ \\
\hline $21-50(54.60 \%)$ & $5(4.1 \%)$ & $71(58.7 \%)$ & $16(13.2 \%)$ & $29(24.0 \%)$ & $24(19.8 \%)$ & $97(80.2 \%)$ \\
\hline $51-100(6.2 \%)$ & $6(5.5 \%)$ & $79(71.8 \%)$ & $6(5.5 \%)$ & $19(17.3 \%)$ & $29(26.4 \%)$ & $81(73.6 \%)$ \\
\hline$>100(6.2 \%)$ & $2(11.1 \%)$ & $15(83.3 \%)$ & $1(5.6 \%)$ & $0(0.0 \%)$ & $5(27.8 \%)$ & $13(72.2 \%)$ \\
\hline Total & $15(4.6 \%)$ & $179(55.2 \%)$ & $40(12.3 \%)$ & $90(27.8 \%)$ & $69(21.3 \%)$ & $255(78.7 \%)$ \\
\hline \multicolumn{4}{|c|}{$\chi_{9}^{2}=71.90$} & & \multicolumn{2}{|c|}{$\begin{array}{c}\chi_{3}^{2}=4.26 \text { [p>0.05; Two-Tailed] }^{*} \\
\text { Insignificant }\end{array}$} \\
\hline \multicolumn{7}{|c|}{ Table 4. Distribution according to Travelling Distance of New-Borns } \\
\hline \multicolumn{7}{|c|}{$\begin{array}{l}{ }^{* *} \text { The association is highly significant for } 9 \mathrm{~d} \text {. f. at the } 0.001 \text { level. }{ }^{*} \text { The association isn't significant (insignificant) for } 3 \mathrm{~d} \text {. f. at the } \\
0.05 \text { level. The figures in parenthesis denote corresponding. }\end{array}$} \\
\hline
\end{tabular}

\begin{tabular}{|c|c|c|c|c|c|c|}
\hline \multirow[b]{2}{*}{ Travelling Time } & \multicolumn{3}{|c|}{ Hypothermia (in ${ }^{\circ} \mathrm{C}$ ) } & \multirow{2}{*}{\begin{tabular}{|c|} 
Normothermic \\
$>36.4$
\end{tabular}} & \multirow{2}{*}{\begin{tabular}{|c|} 
Hypoglycaemia \\
$\leq 40$ \\
mg $\backslash \mathrm{dl}$ \\
\end{tabular}} & \multirow{2}{*}{$\begin{array}{c}\text { Normoglycemia } \\
>40 \\
\text { mg } \backslash \mathrm{dl}\end{array}$} \\
\hline & $<32$ & $32-36$ & $36-36.4$ & & & \\
\hline$\leq 30$ Min. $(21.6 \%)$ & $2(2.9 \%)$ & $15(21.4 \%)$ & $14(20.0 \%)$ & $39(55.7 \%)$ & $9(12.9 \%)$ & $61(87.1 \%)$ \\
\hline 30 Min-1 Hour (33.3\%) & $5(4.6 \%)$ & $54(50.0 \%)$ & $16(14.8 \%)$ & $33(30.6 \%)$ & $18(16.7 \%)$ & $90(83.3 \%)$ \\
\hline 1 Hour -2 Hour $(29.0 \%)$ & $6(6.4 \%)$ & $68(72.3 \%)$ & $8(8.5 \%)$ & $12(12.8 \%)$ & $26(27.7 \%)$ & $68(72.3 \%)$ \\
\hline$>2$ Hour $(16.0 \%)$ & $2(3.8 \%)$ & $42(80.8 \%)$ & $2(3.8 \%)$ & $6(11.5 \%)$ & $16(30.8 \%)$ & $36(69.2 \%)$ \\
\hline Total & $15(4.6 \%)$ & $179(55.2 \%)$ & $40(12.3 \%)$ & $90(27.8 \%)$ & $69(21.3 \%)$ & $255(78.7 \%)$ \\
\hline \multicolumn{5}{|c|}{$\chi_{9}^{2}=67.85$} & \multicolumn{2}{|c|}{$\begin{array}{c}\chi_{3}^{2}=9.41 \quad \begin{array}{c}\text { [p<0.03; Two-Tailed] } \\
\text { Significant }^{*}\end{array} \\
\\
\end{array}$} \\
\hline \multicolumn{7}{|c|}{ Table 5. Distribution according to Travelling Time of New-Borns } \\
\hline
\end{tabular}




\begin{tabular}{|c|c|c|c|c|}
\hline \multirow{2}{*}{ Method } & \multicolumn{3}{|c|}{ Hypothermia } & Normothermic \\
\hline & $<32^{\circ} \mathrm{C}$ & $32-36^{\circ} \mathrm{C}$ & $36-36.4^{\circ} \mathrm{C}$ & $>36.4^{\circ} \mathrm{C}$ \\
\hline Cotton Cloth (51.2\%) & $9(5.4 \%)$ & $90(54.2 \%)$ & $18(10.8 \%)$ & $49(29.5 \%)$ \\
\hline Blanket $(8.0 \%)$ & $0(0.0 \%)$ & $13(50.0 \%)$ & $6(23.1 \%)$ & $7(26.9 \%)$ \\
\hline Shawl (17.9\%) & $1(1.7 \%)$ & $37(63.8 \%)$ & $7(12.1 \%)$ & $13(22.4 \%)$ \\
\hline Blanket/Cotton Cloth (16.7\%) & $2(3.7 \%)$ & $23(42.6 \%)$ & $9(16.7 \%)$ & $20(37.0 \%)$ \\
\hline Inadequate $(6.2 \%)$ & $3(15.0 \%)$ & $16(80.0 \%)$ & $0(0.0 \%)$ & $1(5.0 \%)$ \\
\hline Total & $15(4.6 \%)$ & $179(55.2 \%)$ & $40(12.3 \%)$ & $90(27.8 \%)$ \\
\hline \multicolumn{5}{|c|}{$\chi_{12}^{2}=24.15_{[\mathbf{p}<0.02 ; \text { Two-Tailed] Significant }}{ }^{*}$} \\
\hline
\end{tabular}

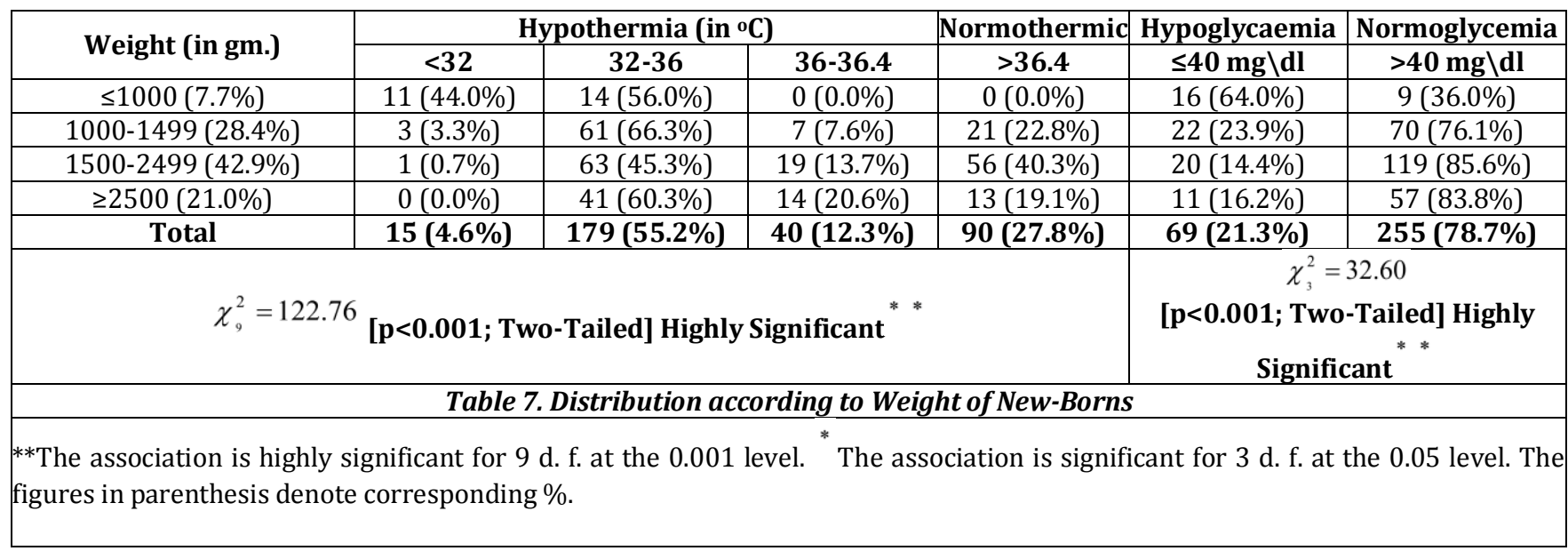

Most of the new born $(195,60.2 \%)$ were referred to our centre in view of tertiary care requirement while (129, $39.8 \%$ ) new-borns had financial issues so brought to us. More than one - third of the new-borns (38.6\%) had referral note which was incomplete. A complete referral note was maintained in $27.8 \%$, while $33.6 \%$ came without any referral note at the time of admission.

Our study revealed that out of 324 babies, 33 babies $(10.2 \%)$, were transported in incubator, 20 babies with infusion pumps carrying maintenance fluid and lifesaving drugs like Prostaglandin E1 (8.9\%), 21 babies shifted on IPPV with endo tracheal tube in situ (6.5\%) and Bag \& mask and nasal prongs were used in $0.3 \%$ and $0.3 \%$ cases respectively. Pulse oxymeter was note used in any of the transportation.

In our study maximum number of babies accompanied by a relative only i.e. $50.31 \%$ (163) and $20.68 \%$ (67) with their parent. Only $12.04 \%$ (39) babies accompanied by a welltrained staff during transportation, and remaining $16.98 \%$ (55) with an untrained staff. In only 85 cases i.e. $26.24 \%$ telecommunication done while rest 239 i.e. $73.76 \%$ shifted to us without any pre - information about the patient.

In our study the commonest reason for admission in the cases studied was Prematurity and low birth weight (130, $40.12 \%)$ including extreme premature $(26,8.03 \%)$ infants. It was followed by neonatal hyper- bilirubinaemia in about 84 cases $(35.93 \%)$. Rest out born detected with: Sepsis in 79 cases $(24.38 \%)$, birth asphyxia in 49 cases (15.12\%), Hyaline membrane disease in 36 cases (11.11\%), 24 with Meconium aspiration syndrome (7.41\%), shock in 20 cases $(6.17 \%)$, Pneumonia in 10 cases $(3.09 \%)$ and 12 cases $(3.70 \%)$ with some surgical causes like trachea- oesophageal fistula,

diaphragmatic hernia etc. While 67 babies (20.68\%) had miscellaneous diagnosis including congenital heart disease, dehydration fever, hypernatremic dehydration, refractory hypoglycaemia etc.

\begin{tabular}{|c|c|c|c|c|c|}
\hline \multirow[b]{2}{*}{ Abnormality } & \multicolumn{3}{|c|}{ Outcome } & \multirow{2}{*}{$\begin{array}{c}\text { Chi }^{2} \\
\text { Value }\end{array}$} & \multirow[b]{2}{*}{ LOS } \\
\hline & Discharge & Expired & $\begin{array}{l}\text { DOR/ } \\
\text { LAMA }\end{array}$ & & \\
\hline $\begin{array}{c}\text { Severe } \\
\text { Hypothermia }\end{array}$ & $\begin{array}{c}2 \\
(13.3 \%)\end{array}$ & $\begin{array}{c}11 \\
(73.3 \%)\end{array}$ & $\begin{array}{c}2 \\
(13.3 \%)\end{array}$ & \multirow{4}{*}{50.30} & \multirow{4}{*}{$\begin{array}{c}\mathrm{p}<0.001 \\
* *\end{array}$} \\
\hline $\begin{array}{c}\text { Moderate } \\
\text { Hypothermia }\end{array}$ & $\begin{array}{c}94 \\
(52.5 \%)\end{array}$ & $\begin{array}{c}51 \\
(28.5 \%)\end{array}$ & $\begin{array}{c}34 \\
(19.0 \%)\end{array}$ & & \\
\hline $\begin{array}{c}\text { Mild } \\
\text { Hypothermia }\end{array}$ & $\begin{array}{c}28 \\
(70.0 \%)\end{array}$ & $\begin{array}{c}1 \\
(2.5 \%)\end{array}$ & $\begin{array}{c}11 \\
(27.5 \%)\end{array}$ & & \\
\hline Normothermia & $\begin{array}{c}69 \\
(76.7 \%)\end{array}$ & $\begin{array}{c}8 \\
(8.9 \%)\end{array}$ & $\begin{array}{c}13 \\
(14.4 \%)\end{array}$ & & \\
\hline Hypoglycaemia & $\begin{array}{c}35 \\
(50.7 \%) \\
\end{array}$ & $\begin{array}{c}24 \\
(34.8 \%) \\
\end{array}$ & $\begin{array}{c}10 \\
(14.5 \%) \\
\end{array}$ & \multirow[b]{2}{*}{8.54} & \multirow{2}{*}{$p<0.02^{*}$} \\
\hline Normoglycemia & $\begin{array}{c}158 \\
(62.0 \%)\end{array}$ & $\begin{array}{c}47 \\
(18.4 \%)\end{array}$ & $\begin{array}{c}50 \\
(19.6 \%)\end{array}$ & & \\
\hline
\end{tabular}

Table 9. Distribution according to Outcome of New-Borns **The association is highly significant for $6 \mathrm{~d}$. f. at the 0.001 level. ${ }^{*}$ The association is significant for $2 \mathrm{~d}$. f. at the 0.02 level. The figures in parenthesis denote corresponding \%. [LOS Level of Significance]

The mean duration of stay in hospital of new born was observed to be 8.65 days with a standard deviation of \pm 7.23 days. In moderate hypothermia group, $47.5 \%$ babies stayed for $<7$ days, $30.2 \%$ for 7 - 15 days and $6.7 \%$ for $>15$ days. In severe hypothermic group stay was $80 \%, 13.3 \%$ and $6.7 \%$ respectively along with $45 \%, 33.3 \%$ and $10 \%$ in mild hypothermia group. (For this a significant $P$ value obtained $p$ $<0.03$.). In second group of hypoglycaemia, babies stayed with a duration of < 7, $7-15$ and $>15$ days was $50.7 \%, 27.5 \%$ and $21.7 \%$ respectively without a significant association ( $p>$ 0.05; two tailed). 


\section{DISCUSSION}

The aim of the present study was to assess the effect of available Neonatal Transport System on morbidity and mortality of out born neonates; including modes, organized transport, special needs and care during transport. We also tried to discuss the effects of these determinants have on the overall survival of these new-borns \& prognosis of other neonatal conditions.

Poddutoor et $\mathrm{al}^{7}$ found the incidence of hypoglycaemia (20.5\%), hypothermia (38.4\%), hypoxia (21.7\%) and apnoea $(6.4 \%)$ were significantly more in babies who had come on their own. Gupta et $\mathrm{al}^{8}$ found babies who arrived by selftransport were $65.5 \%$ hypothermic, $32 \%$ hypoglycaemic, $16 \%$ cyanosed, $30.9 \%$ with CRT $>3$ sec and $27.6 \%$ with acidosis at the time of arrival to NICU. In the present study, out of 324 approximately $72.2 \%$ found hypothermic, $21.3 \%$ hypoglycaemic, $21.9 \%$ hypoxic and $19.1 \%$ with poor perfusion. Out of these 234 hypothermic new-borns, 179 $(76.5 \%)$ had moderately hypothermia, 40 (17.1\%) with mild hypothermia and 15 (6.4\%) with severe hypothermia.

NB Mathur et $\mathrm{al}^{9}$ found that home delivered babies had incidence of moderate hypothermia 33\% \& severe hypothermia $4 \%$ \& hospital delivered were $29 \%$ moderately hypothermic.

Similarly, in home delivered babies of our study incidence of moderate hypothermia is maximum $(8,50 \%)$ followed by severe hypothermia $(1,6.3 \%)$. While in tertiary care center deliveries, moderate hypothermia was found in $(1,33.3 \%)$ without any case with severe hypothermia.

In the present study, major mode of transport was ambulance in which $50.9 \%$ babies were transported. While in a study of Sehgal et al,10 $14 \%$ babies were transported with cycle rickshaw, $50.9 \%$ with auto, $27 \%$ with bus \& $4 \%$ with two-wheeler. Out of these 165 babies, who transported in ambulance, $57.6 \%$ had moderate hypothermia, $10.9 \%$ mild hypothermia and $4.2 \% \& 27.3 \%$ with severe and euthermia respectively.

In our study severe hypothermia reported in 7 cases $(4.2 \%)$, those who transported in ambulance, as most of them 5 new-borns were extremely low birth weight babies with complex disease pathology.

Gustavo et al11 found more clinical deterioration in newborns who travelled $>60 \mathrm{~km}$ i.e. $21 \%$ vs. $16 \%$. Poddutoor et al7 found $45 \%$ of babies transported from a longer distance were ventilated as compared to $39 \%$ of babies transported within the city, including 24-hour survival rates for short distance transport. In the present study most of the babies came from 21 - $50 \mathrm{~km}$ of Indore. Incidence of severe and moderate hypothermia was maximum with travelling distance $>100 \mathrm{~km}$ i.e. $11.1 \%$ \& $83.3 \%$ respectively.

Similarly, hypoglycaemia found mostly in group who

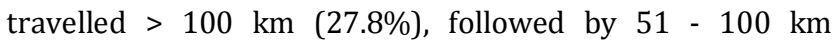
(26.4\%), $21-50 \mathrm{~km}(19.8 \%)$ and $<20 \mathrm{~km}(14.7 \%)$. Hypoxia was mostly seen in $29.1 \%$ cases who travelled $51-100 \mathrm{~km}$ followed by $22.2 \%$ cases of $>100 \mathrm{~km}$ distance. Incidence of prolonged CRT was highest in babies travelled $>100 \mathrm{~km}$ and 51 - $100 \mathrm{~km}$ i.e. $33.3 \%$ and $24.5 \%$.

We found hypothermia was mostly associated with those travelled $>2$ hour (80.8\%) and 1- 2-hour group (72.3\%). But severe hypothermia is seen maximum in 1-2-hour group i.e. $6.4 \%$. Breno et $\mathrm{al}^{3}$ observed mean travelling time of 79 minutes. Similarly, Mori et al ${ }^{12}$ reported that neonates with a long duration of transport had 79\% higher odd of death. They found a strong evidence that those transported for $>90 \mathrm{~min}$ had more than twice the rate of neonatal death (RR 2.26; 95\% CI 1.26 - 4.04) and some evidence that those transported for between 60 - $89 \mathrm{~min}$ had an $80 \%$ higher rate of neonatal death (RR 1.81; 95\% CI 1.07 - 3.06). In our study hypoglycaemia was found mostly in those babies who travelled for $>2$ hours (30.8\%) followed by $27.7 \%$ who travelled for 1 - 2 hours. This strong association in study itself proves the importance of feeding babies during transportation (If feeding is not contraindicated for some disease pathology). Out of 324 , none of the baby was fed during transportation in our study.

We found most of babies, $28.7 \%$ were severely hypoxic who travelled for 1- 2 hour while moderate hypoxia was max $73.1 \%$, whom travelled for $>2$ hour. Circulatory abnormalities were found highest in those who travelled for 1-2 hour i.e. $26.6 \%$. We also found that travelling distance and duration were directly proportionate to hypothermia and other parameters.

NB Mathuret $\mathrm{al}^{9}$ found that $36 \%$ babies were transported naked. Only $5 \%$ of the neonates had head covered with cap. None of the neonates were wearing gloves \& stockings at admission. We distributed according to the method kept to keep baby warm during transport. Majority of babies were covered with plain cotton cloth to keep them warm i.e. 51.2\%, and in them hypothermia was found in $54.2 \%$. Inadequate dressing had highest incidence of severe (15\%) and moderate hypothermia $(80 \%)$.

Yoder et $\mathrm{al}^{13}$ reported higher incidence of hypothermia and grade III/ IV bleeding were seen in transported infants between 1001 - 2000 gm compared with maternal transports and all inborn infants.

In present study the mean weight of new-born was $1889.56 \mathrm{gm}$ with a standard deviation of $706.52 \mathrm{gm}$. Hypoglycaemia was maximum in $<1000$ gm neonates i.e. $64 \%$. We found incidence of moderate hypothermia was not much varied in all groups but highest in $1000-1499$ gm babies i.e. $66.3 \%$. While severe hypothermia was highest in babies < 1000 gm (44\%), none of the baby > 2500 gm found severe hypothermic.

We found hypoxia was more in $>2500$ gm babies, as out of total 68 neonates of weight $>2500$ gm in our study, presented with some congenital heart disease and MAS. Babies with < 1000 gm had $28.08 \%$ severe hypoxia. Poor perfusion was found highest in $<1000$ gm babies (40\%) followed by $21.7 \%$ in 1000 - 1499 gms. In present study $60 \%$ babies were referred in a need of tertiary care requirement while in $39.8 \%$ babies it was matter of financial constraints. There was no referral note from the referral centre in $33.6 \%$ babies, which give us some idea regarding the pre-transfer status, medications and specific investigations. While $38.6 \%$ had a referral note but it was not complete, only $27.8 \%$ babies had a complete referral note. Similarly, in the study of A Sehgal, ${ }^{10}$ they found none of the referrals were accompanied by a trained personnel \& referral notes.

In study of Breno $\mathrm{F}$ Araujo et $\mathrm{al}^{3}$ equipment used during transport were incubator / crib with temperature control in $57.4 \%$, infusion pumps in $13.1 \%$, glucometer in $21.3 \%$, oximeter in $49.2 \%$, bag \& mask in $34.4 \%$ and none with intubation material \& hood. Gupta et al 8 also compared their retrieved new-born who transported with a well-equipped 
portable incubator, ventilator, monitors, oxygen supply and infusion pumps vs. self-transported babies.

In our study 33 babies (10.2\%) were transported in an incubator, 20 with infusion pumps (6.2\%) providing maintenance fluid, vasopressors in 2 and prostaglandin E1 in 2 babies, intubation material in 21 (6.5\%), emergency kit including emergency medications in 29 babies (8.9\%) with less use of nasal prongs and bag \& mask only in $1(0.3 \%)$ and 1 cases $(0.3 \%)$ respectively. Almost half of the new-borns $49.4 \%$ had oxygen supply during transport.

We found that babies mostly accompanied by their relatives $50.6 \%$ during the transport. Other persons were parents $20.7 \%$, untrained staff $16.98 \%$ and very less with a well-trained staff in neonatal transport i.e. $12.04 \%$. None of the referral accompanied with a paediatrician. Richard A Orr et al ${ }^{14}$ reported unplanned events were more among patients transported by a non-specialized team (61\% vs. $1.5 \%)$.

Pre-information in form of Tele communication was provide only in $26.24 \%$ referral cases that helps us to prearrange beds and basic equipment required for that particular case. Breno Araujo et $\mathrm{al}^{3}$ obtained information via a phone call to the physician who treated the new-born in the hospital of origin, where some data were missing in specific cases.

Podduttor et al $^{7}$ mentioned the disease profile of transported neonates with multiple problems i.e. prematurity (59.4\%), HMD (17.2\%), sepsis (42.2\%), MAS (3.1\%), birth asphyxia (12.5\%), surgical (6.3\%), IUGR (6.3\%) and miscellaneous other causes $(37.5 \%)$ cases. In our study highest cause for the referral was prematurity (40.12\%) and low birth weight care including extreme prematurity (8.03\%).

Suzana et al 15 in Brazil found that $52.5 \%$ of moderate hypothermia had deteriorated to death while only $7 \%$ of no hypothermia deteriorated to death. NB Mathur ${ }^{9}$ observed fatality in $39.3 \%$ in mild, $51.6 \%$ in moderate \& $80 \%$ in severely hypothermic babies.

In present study the highest mortality found in severe hypothermia group $73.3 \%$ with lowest in mild hypothermia group $2.5 \%$. While maximum babies were discharged from normal and mild hypothermia group i.e. $76.7 \%$ \& $70 \%$ respectively. While in hypoglycaemic babies $50.7 \%$ discharged, $34.8 \%$ expired and $14.5 \%$ went LAMA/ DOR.

We found death was significantly higher in severe hypoxia group in comparison to moderate hypoxia i.e. $45.1 \%$ and $18.2 \%$ respectively. Mortality was higher in babies with prolonged CRT $45.2 \%$.

Gupta et al 8 compared the survival of self-transported and retrieved out born at 48 hours. In our study, we found highest stay in moderate hypothermia group $22.3 \%$. Babies with severe hypothermia had significantly higher mortality within initial 7 days, so they form the bulk of $<7$ days stay. While $50.7 \%$ babies with hypoglycaemia had a shorter duration of stay in NICU. Similarly, due to increased mortality in severe hypoxia and poor perfusion, their stay in NICU was shorter.

\section{CONCLUSION}

In our study, most of sick neonates were transferred by their relatives, parents or paramedical personnel either in a private vehicle or poorly equipped ambulance. Though, half of new-borns were transported to us in an ambulance, which shows improvisation of the transport facility, still they are lacking in other basic equipment like incubators, infusion pumps, pulse oximeter, emergency medication with intubation material which severely affects the neonatal outcome. Even when equipment is available, very few were accompanied by trained transport personnel.

The information given to the referral hospital is in most cases insufficient and given by a nurse or paramedical staff rather than a physician. Of the out born transported neonates in our study, hypothermia was most frequently observed in as high as three-fourth of the babies. Other abnormalities found in these babies were hypoxia, hypoglycaemia \& poor perfusion. None of the babies were fed during transport. Also, method of covering strongly correlated with the occurrence and degree of hypothermia.

Regarding the effects of different variables on hypothermia, an increased occurrence of hypothermia was seen in majority of the babies referred from district hospitals in ambulances. This sample predominantly had VLBW \& sick babies. The other variables showed positive correlation for occurrence \& severity of hypothermia had longer travelling distances \& durations. Our study also highlights that longer distance \& duration increases the incidence of hypoxia \& hypoglycaemia.

When we looked at the overall mortality and the four variables at time of arrival, hypothermia, hypoglycaemia, oxygenation and poor perfusion are significantly associated with an adverse outcome amongst transported neonates and hypothermia was detected to be the most significant risk factor.

To conclude, efforts for improving transport conditions of sick new-borns include the following practices-

a. Hypothermia can be prevented by methods like incubators, radiant heater, heated water-filled mattresses, kangaroo mother care.

b. Neonatal hypoglycaemia, that causes long term neurological sequelae, can be simply prevented by giving IV boluses before transport, maintaining IV access and continuous fluid infusion during transport and feeding of a stable neonate.

c. Hypoxia can be prevented with increasing use of pulse oximeter \& oxygen support at an early stage.

d. All neonatal health care facilities should have some basic referral guidelines i.e. pre-communication with the referral institute \& parents, reason for transfer including detailed perinatal history, current patient status, referral note with provisional diagnosis, lab data \& therapy given so far.

e. Educational efforts related to neonatal transport; which needs participation of healthcare personnel in program like NRP (Neonatal Resuscitation Program) to improve basic skills of these paramedical personnel play an important role in safe transport of neonates.

\section{REFERENCES}

[1] Kempley ST, Sinha AK, Thames Regional Perinatal Group. Census of neonatal transfers in London and the South East of England. Arch Dis Child Fetal Neonatal Ed 2004;89(6):F521-F6.

[2] Chung-Ming C, Chyh-Kae H. Neonatal vital statistics and transport in Hualien Country. Clinical Neonatology 1998;5(1):10-3. 
[3] Araujo BF, Zatti H, Filho OPF, et al. Effect of place of birth and transport on morbidity and mortality of preterm new-borns. J Pediatr (Rio J) 2011;87(3):25762.

[4] Rashid A, Bhuta T, Berry A. A regionalized transport service, the way ahead? Arch Dis Child 1999;80(5):488-92.

[5] Shah PS, Shah V, Qiu Z, et al. Improved outcomes of out born preterm infants if admitted to perinatal centers versus freestanding pediatric hospitals. J Pediatr 2005;146(5):626-31.

[6] Bang AT, Bang RA, Baitule SB, et al. Effect of home based neonatal care and management of sepsis on neonatal mortality: field trial in rural India. Lancet 1999;354(9194):1955-61.

[7] Kumar PP, Kumar CD, Venkatlakshmi A. Long distance neonatal transport - the Need of the hour. Indian Pediatrics 2008;45(11):920-2.

[8] Gupta P, Kulkarni A, Kaul S, et al. Comparative analysis of retrieved v/s Self transported out born neonates. NEO/14(0).

[9] Mathur NB, Krishnamurthy S, Mishra TK. Evaluation of WHO classification of hypothermia in sick extramural neonates as predictor of fatality. Journal of Tropical Pediatrics 2005;51(6):341-5.
[10] Sehgal A, Roy MS, Dubey NK, et al. Factors contributing to outcome in new-borns delivered out of hospital and referred to a teaching institution. Indian Pediatr 2001;38(11):1289-94.

[11] Goldsmit G, Rabasa C, Rodriguez S, et al. Risk factors associated to clinical deterioration during the transport of sick new-born infants. Arch Argent Pediatrics 2012;110(4):304-9.

[12] Mori R, Fujimura M, Shiraishi J, et al. Duration of inter facility neonatal transport and neonatal mortality: systemic review and cohort study. Pediatric International 2007;49(4):452-8.

[13] Yoder BA. Long distance perinatal transport. American Journal of Perinatology 1992;9(2):75-9.

[14] Orr RA, Felmet KA, Han Y, et al. Pediatric specialized transport teams are associated with improved outcomes. Pediatrics 2009;124(1):40-8.

[15] Da Mota Silveira SM, De Mello GMJ, De Arruda VS, et al. Hypothermia on admission: a risk factor for death in new-borns referred to the Pernambuco Institute of Mother and Child Health. Journal of Tropical Pediatrics 2003;49(2):115-20. 